\title{
Myosin VI is a modulator of androgen-dependent gene expression
}

\author{
ILDIKÓ LOIKKANEN ${ }^{1}$, KATJA TOLJAMO ${ }^{1}$, PASI HIRVIKOSKI ${ }^{2}$, \\ TIMO VÄISÄNEN ${ }^{1,2}$, TIMO K. PAAVONEN ${ }^{3}$ and MARKKU H. VAARALA ${ }^{1,4}$
}

\author{
${ }^{1}$ Department of Pathology, University of Oulu; ${ }^{2}$ Department of Pathology, Oulu University Hospital, Oulu; \\ ${ }^{3}$ Department of Pathology, University of Tampere and Tampere University Hospital, Tampere; \\ ${ }^{4}$ Department of Surgery, Division of Urology, Oulu University Hospital, PO Box 21, 90029 OYS, Finland
}

Received June 5, 2009; Accepted July 30, 2009

DOI: 10.3892/or_00000526

\begin{abstract}
Myosin VI, one of the so-called unconventional myosins, is an actin-based molecular motor involved in intracellular vesicle and organelle transport. In human prostate, myosin VI is expressed in prostate epithelium. We examined the effect of myosin VI downregulation in the LNCaP human prostate cancer cell line using an RNA interference approach. Further, the expression of myosin VI in human prostate tissue was examined using immunohistochemistry. The expression of androgen receptor (AR) and E-cadherin was examined in myosin VI knocked-down cells and control cells. We determined ${ }^{3} \mathrm{H}$-testosterone uptake in the myosin knocked-down LNCaP cells. Next, we cotransfected LNCaP cells with the myosin VI-specific small interfering RNA (siRNA) duplex and an androgen-responsive luciferase reporter construct and then measured luciferase activity after androgen induction. To clarify whether myosin VI and the AR are interacting proteins, we performed immunoprecipitation studies using myosin VI and AR polyclonal antibodies in androgeninduced LNCaP cells. We confirmed previous results of myosin VI overexpression in human prostate cancer tissue, as in some cases malignant epithelium was more intensively stained than benign epithelium. We found that the expression of AR decreased as a result of myosin VI knock-down. Decreased myosin VI levels did not significantly influence the testosterone uptake of the $\mathrm{LNCaP}$ cell line. Instead, we noted a decreased activity of the androgen-regulated mouse mammary tumor virus promoter-reporter vector construct in LNCaP cells cotransfected with myosin VI siRNA duplexes. Finally, we detected the interaction between AR and myosin VI by immunoprecipitation. We propose that myosin VI is a
\end{abstract}

Correspondence to: Dr Markku Vaarala, Department of Surgery, Division of Urology, PO Box 21, FIN-90029 OYS, Finland E-mail: markku.vaarala@oulu.fi

Key words: prostate cancer, androgen receptor, myosin VI, gene expression regulation modulator of androgen-dependent gene transcription via interaction with the AR. Thus, myosin VI is a potential therapeutic target for prostate cancer as it could be used as a modulator of AR-dependent gene expression.

\section{Introduction}

Myosin VI is an actin-based motor protein that moves in a reverse direction when compared to the other known myosins, i.e. it moves from the plasma membrane into the cell and away from the surface of internal organelles such as the Golgi complex (1). It has been shown to have functional roles in endocytosis (2), migration (3) and cell-cell interactions (4), as well as in the modulation of RNA polymerase II-dependent transcription (5). Myosin VI has been linked to ovarian and prostate cancer. Inhibiting myosin VI expression in high-grade ovarian carcinoma cells impeded cell spreading and migration in vitro (3). Similarly, in prostate cancer the inhibition of myosin VI expression impeded cell migration in vitro (6). Myosin VI showed cancer-specific overexpression in clinical prostate samples and positively correlated with the presence of androgen receptor (AR) in established cell lines (6). Further, myosin VI is overexpressed in proliferative inflammatory atrophy (PIA) and in prostatic intraepithelial neoplasia (PIN) (6), which are precursor lesions for prostate cancer. Myosin VI has also been linked to genetic rearrangements in prostate cancer (7). Androgens are a prerequisite for the development of prostate cancer, which is the most common malignancy of men in the Western world. The action of androgens on gene expression is mediated via the AR.

Using a cDNA array, we have previously detected differential expression of myosin VI mRNA in LNCaP cells when comparing expressed genes in cells producing prostatespecific antigen (PSA) to cells transformed to an androgenindependent variant with no PSA production. Myosin VI was overexpressed in the non-transformed LNCaP cells (8). We thus studied the expression of myosin VI in prostate cancer tissue using a commercially available myosin VI antibody. We found abundant expression of myosin VI in a panel of prostate cancer tissues. Expression was localized in the cytosol, concentrating on the cell membrane of epithelial cells. We downregulated myosin VI in LNCaP cells by using an RNA interference (RNAi) approach and studied cellular responses. 
Our results suggest myosin VI modulates androgen-dependent gene expression by interaction with the AR.

\section{Materials and methods}

Patient samples and immunohistochemistry. Archival prostate samples were formalin-fixed and paraffin-embedded. For immunohistochemical studies, the expression of myosin VI was determined in 20 consecutive samples of prostatic needle biopsies together with a multitissue block containing 32 acinar adenocarcinomas of different Gleason grades. Paraffinembedded tissue sections were subjected to heat induced antigen retrieval by boiling for $15 \mathrm{~min}$ in $1 \mathrm{mM}$ EDTA, $\mathrm{pH} 8.0$. Sections were then incubated for 30 min with 1:250 dilution of anti-myosin VI antibody (clone MUD-19, Sigma Aldrich, St. Louis, MO). Bound antibodies were visualized using an EnVision+ System-HRP (DakoCytomation) detection kit, as instructed by the manufacturer, followed by hematoxylin counterstaining. For antecedent diagnostic purposes, additional stainings for high molecular weight cytokeratin (34ßE12, DakoCytomation, Glostrup, Denmark) and $\alpha$-Methyl-CoA racemase (P504S, Biocare Medical, Concord, CA) had been done to strengthen the morphological diagnosis based on hematoxylin and eosin-stained slides. Immunohistochemical staining was evaluated simultaneously by two observers (P.H. and M.H.V.) and a consensus was reached. The local Ethics Council approved the research plan.

Cell culture. The prostate cancer cell line LNCaP (CRL-1740) was purchased from American Type Culture Collection (ATCC, Manassas, VA). Cell cultures were maintained in RPMI-1640 (Sigma-Aldrich) supplemented with $10 \mathrm{mM}$ HEPES, $1 \mathrm{mM}$ sodium pyruvate, $2.5 \mathrm{~g} / \mathrm{l} \mathrm{D}$-glucose and $1 \%$ penicillin-streptomycin (Invitrogen-Gibco, Carlsbad, CA) with $10 \%$ fetal bovine serum (HyClone, Logan, UT) at $37^{\circ} \mathrm{C}$ in a humidified atmosphere of $5 \% \mathrm{CO}_{2}$.

Transfections. In the LNCaP cells, myosin VI was knockeddown by reverse transfection of Stealth small interfering RNA (siRNA) duplex oligonucleotides (Invitrogen) (Pair 1: UUA UGG AGC AGU GUG GCU UCA UUUA and UAA AUG AAG CCA CAC UGC UCC AUAA, pair 2: AAU UUG AGC ACC UUC AAA GUG GUGG and CCA CCA CUU UGA AGG UGC UCA AAUU) with the Lipofectamine 2000 transfection reagent (Invitrogen) in 24-well plate format following the manufacturer's instructions. Control transfections were performed under the same conditions using a pre-designed Stealth RNAi Negative Control (Invitrogen). Cells were collected and analyzed $48 \mathrm{~h}$ after transfection.

For androgen induction, cells were treated with $1 \mathrm{nM}$ R1881 (PerkinElmer, Boston, MA) or with the corresponding amount of ethanol for $24 \mathrm{~h}$, starting $24 \mathrm{~h}$ after the RNAi reverse transfection. For the androgen-dependent gene expression studies, during the siRNA reverse transfection procedure, LNCaP cells were cotransfected with 20 ng mouse mammary tumor virus (MMTV) promoter in pGL3-Basic (a gift from Professor J. Palvimo, University of Kuopio, Kuopio, Finland) and with a second reporter plasmid, pRL-TK (Promega, Madison, WI), which provided an internal control for transfection efficiency. The luciferase activities were measured using the Dual-luciferase reporter assay system (Promega).

Western blotting. LNCaP cells were lysed in a lysis buffer containing $20 \mathrm{mM}$ Tris- $\mathrm{HCl}$ (pH 7.5), $150 \mathrm{mM} \mathrm{NaCl}, 1 \mathrm{mM}$ EDTA (pH 8.0), 1 mM EGTA (pH 7.9), 1\% Triton-X100, $2.5 \mathrm{mM}$ sodium pyrophosphate, $1 \mathrm{mM}$ B-glycerophosphate, $1 \mathrm{mM} \mathrm{Na}_{3} \mathrm{VO}_{4}$ and a protease inhibitor cocktail (Sigma). The protein extract was separated by $10 \%$ SDS-PAGE and transferred onto a nitrocellulose membrane. Membranes were blotted with monoclonal anti-myosin VI (Sigma), anti-Ecadherin (Zymed, San Francisco, CA) and polyclonal anti-AR (Santa Cruz Biotechnology, Santa Cruz, CA). The secondary antibodies were goat anti-mouse and anti-rabbit IgG-HRPs from Santa Cruz.

Testosterone uptake studies. The serum in the medium of the control and myosin VI downregulated (RNAi) LNCaP cells was substituted with charcoal-treated fetal bovine serum for $24 \mathrm{~h}$. Cells were then incubated with plain media or with media supplemented with $1 \mu \mathrm{M}$ unlabeled testosterone, for $15 \mathrm{~min}$. They were labeled with $10 \mathrm{nM}\left(1,2,6,7-{ }^{3} \mathrm{H}\right)$-testosterone (Amersham Biosciences, Piscataway, $\mathrm{NJ}$ ) for $2 \mathrm{~h}$ at $37^{\circ} \mathrm{C}$. Labeled cells were washed with PBS to remove any unbound ligand. The incorporated radioactivity was determined by scintillation counting. Specific binding $(\mathrm{cpm} / \mu \mathrm{g})$ is defined as the difference in counts between samples incubated with $\left(1,2,6,7-{ }^{3} \mathrm{H}\right)$-testosterone only, as compared to those diluted with a 100 -fold excess 'cold' testosterone.

Immunoprecipitation. Myosin VI and AR were immunoprecipited using polyclonal antibodies (Santa Cruz). The lysis buffer contained $150 \mathrm{mM} \mathrm{NaCl}, 10 \mathrm{mM}$ Tris- $\mathrm{HCl}, 0.1 \%$ Na-deoxycholic acid, $0.1 \%$ SDS, $1 \%$ Triton $\mathrm{X}-100$ and a protease inhibitor cocktail (Sigma). As a negative control, we used rabbit immunoglobulins. Cells were broken with sonication $(2 \times 15 \mathrm{sec})$ and the extract was further incubated on ice for $15 \mathrm{~min}$ and centrifuged for $10 \mathrm{~min}$ at $20,000 \mathrm{x} \mathrm{g}$ at $4^{\circ} \mathrm{C}$. After the precleaning of the supernatant, $1 \mathrm{mg}$ of cell extract was incubated with $5 \mu \mathrm{g}$ of primary antibodies for $2 \mathrm{~h}$ at $4^{\circ} \mathrm{C}$. The immunocomplex was collected with Protein ASepharose (Amersham), washed five times with the lysis buffer, separated through $6 \%$ SDS-PAGE and transferred to PVDF membranes (Millipore, Billerica, MA). The membranes were blotted with anti-myosin and anti-AR antibodies and detected using chemiluminescent reagents (Sigma).

\section{Results}

Myosin VI expression in prostate tissues. We examined the expression of myosin VI in prostate samples using immunohistochemistry. The staining pattern for myosin VI in epithelial cells was cytoplasmic, concentrating on cell membranes. No staining was observed in the fibromuscular stroma. Mostly in benign glands, the staining was emphasized on apical cell membranes. In a few cases of the benign patient samples, the benign epithelium showed no expression. In some cases, malignant epithelium was more intensively stained than benign epithelium (Fig. 1). However, there was no statistically significant difference between the staining of myosin VI in 
Table I. The expression of myosin VI was determined in 20 consecutive samples of prostatic needle biopsies together with a multi-tissue block containing 32 acinar adenocarcinomas of different Gleason grades. ${ }^{\mathrm{a}}$

Myosin VI staining intensity

\begin{tabular}{|c|c|c|c|c|}
\hline & & Negative & $\begin{array}{c}\text { Weak } \\
\text { positive }\end{array}$ & $\begin{array}{c}\text { Strong } \\
\text { positive }\end{array}$ \\
\hline \multirow[t]{2}{*}{ Needle biopsies with benign and malignant tissue $(n=8)$} & Expression in benign tissue & 1 & 0 & 7 \\
\hline & Expression in malignant tissue & 0 & 1 & 7 \\
\hline Needle biopsies with benign tissue only $(n=12)$ & Expression in benign tissue & 0 & 1 & 11 \\
\hline \multirow[t]{4}{*}{ Multitissue block } & Gleason grade 2 & 0 & 3 & 4 \\
\hline & Gleason grade 3 & 1 & 4 & 4 \\
\hline & Gleason grade 4 & 1 & 3 & 2 \\
\hline & Gleason grade 5 & 1 & 1 & 8 \\
\hline
\end{tabular}

aThe intensity of was classified as negative, weak positive and strong positive.

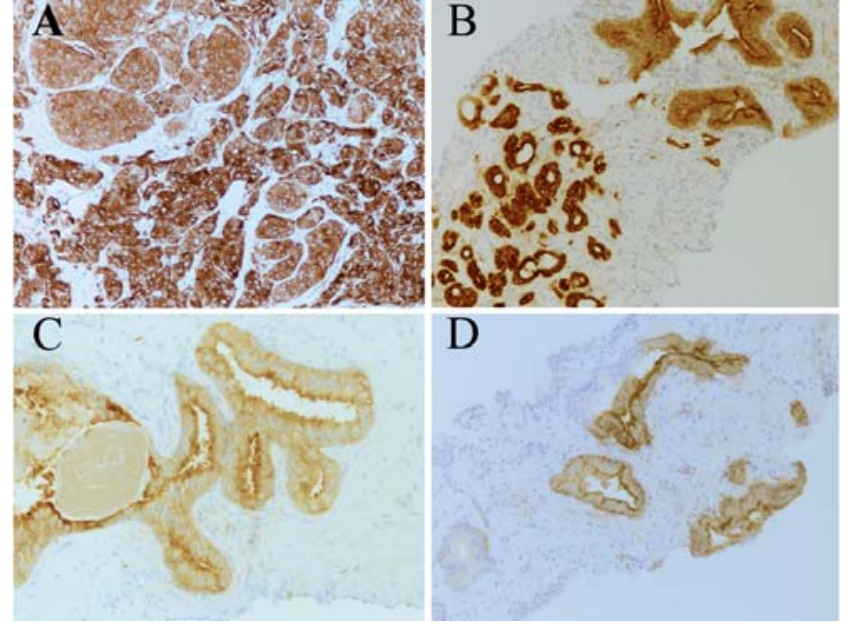

Figure 1. Myosin VI expression in human prostate tissue. Immunohistochemical staining for myosin VI was strong and cytoplasmic in poorly differentiated prostatic adenocarcinoma (A). Malignant glands (lower left) stain more intensively than benign glands (upper right) (B). In benign glands the staining was less intensive and concentrated on apical cell membranes (C) Some benign glands were negative for myosin VI (D). Original magnification: $\mathrm{x} 100(\mathrm{~A}, \mathrm{~B}$ and D) and $\mathrm{x} 200(\mathrm{C})$.

benign and malignant epithelium (Table I and data not shown). Further, there was no association between myosin VI staining and Gleason grade $(\mathrm{P}=0,38$; Fisher's exact test) (Table I). We next evaluated the influence of myosin VI downregulation on the expression of selected proteins in the $\mathrm{LNCaP}$ cell line.

Myosin VI knock-down results in a decrease in AR expression. We have used siRNA duplexes to reduce cellular expression levels of myosin VI in LNCaP cells. Fig. 2 shows a clear downregulation of the myosin VI protein as a result of transfection with the myosin VI-specific siRNA duplex (Pair 1). Transfection with the other myosin VI siRNA duplex (Pair 2) resulted in similar downregulation (data not shown). The expression level of the AR also decreased in the myosin VI knocked-down cells, whereas the level of E-cadherin was not

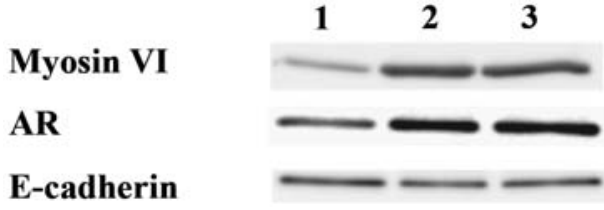

Figure 2. Myosin VI knock-down reduced the expression of androgen receptor (AR) but not of E-cadherin protein levels in LNCaP cells. Western blot analyses of proteins from LNCaP cells treated with myosin VI siRNA duplexes (lane 1), with control siRNA duplexes (lane 2) or non-transfected LNCaP cells (lane 3). The same blots were stained consecutively with different antibodies after removal of the previous antibody by washing.

affected. As some evidence exists for the autoregulation of AR by androgens $(9,10)$, we further examined whether myosin VI affects androgen uptake, which could explain the decreased expression of AR in myosin VI knocked-down cells.

Myosin VI downregulation does not have a significant influence on testosterone uptake in vitro. To explore the possible link between myosin VI and testosterone uptake, we determined ${ }^{3} \mathrm{H}$-testosterone uptake in the myosin knockeddown LNCaP cells. Although we performed repeated experiments (six independent experiments) and there was a slight decrease in the average testosterone uptake in the myosin VI knocked-down cells, we could not prove any significant change compared with the controls. Mean specific binding values (counts per minute $/ \mu \mathrm{g}$ protein) \pm standard deviations for LNCaP cells transfected with control siRNA duplexes or with myosin VI siRNA duplexes were 1050 \pm 514 and $809 \pm 289$, respectively, with $\mathrm{P}=0.35$ (Student's t-test). Therefore, we could not find any evidence of myosin VI disrupting the availability of androgens to the AR. Subsequently, we decided to examine whether myosin VI has any influence on androgen-regulated gene expression.

Myosin VI has a role in androgen-regulated gene transcription. To further clarify if myosin VI has a role in androgen-regulated gene expression, we cotransfected LNCaP cells with the 


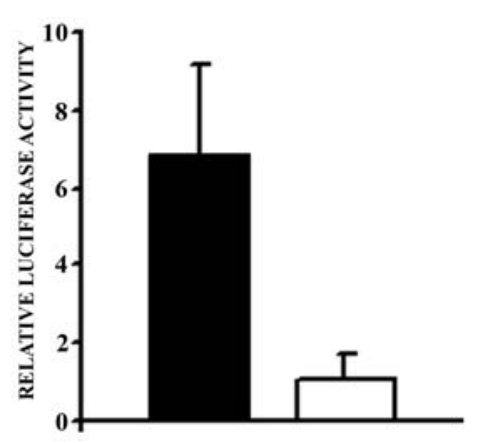

Figure 3. Myosin VI has an effect on the androgen-dependent transactivation of the mouse mammary tumor virus (MMTV) promoter construct in LNCaP cells. LNCaP cells were cotransfected with MMTV promoter in pGL3-Basic and with control siRNA duplexes (solid bar) or myosin VI siRNA duplexes (white bar). Twenty-four hours after transfection the cells were induced with $1 \mathrm{nM} \mathrm{R} 1881$ and luciferase activity was measured after another $24 \mathrm{~h}$. pRL-TK was used as an internal control. The values represent mean \pm standard deviations of six independent experiments. $\mathrm{P}<0.0001$, Student's t-test.

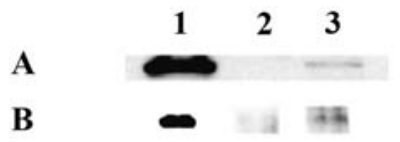

Figure 4. Myosin VI interacts with androgen receptor (AR). Panels A and B present staining with myosin VI antibody and AR antibody, respectively. Lane 1 contains total cell extract, $0.5 \%$ of the amount used for immunoprecipitation and lane 2 the negative control (rabbit $\operatorname{IgG}$ ). Lane 3 contains the AR-immunoprecipitated sample and myosin VI-immunoprecipitated sample in panel A and B, respectively.

myosin VI-specific siRNA duplex and an androgen-responsive luciferase reporter construct and then measured luciferase activity after androgen induction. We found that in the myosin VI knocked-down cells the AR-dependent transactivation of the androgen responsive MMTV promoter construct decreased at least 3-fold, compared with the controls (Fig. 3), suggesting an important role for myosin VI in androgen-dependent gene transcription. As there was no significant change in testosterone uptake after myosin VI knock-down, we assumed that the decreased availability of androgens cannot be the reason for the decreased reporter construct activity. Thus we examined whether myosin VI interacts with AR, as that could explain the decreased ARdependent transactivation after myosin VI knock-down.

Myosin VI interacts with the AR. To clarify whether myosin VI and the AR are interacting proteins, we performed immunoprecipitation studies using myosin VI and AR polyclonal antibodies in androgen-induced $\mathrm{LNCaP}$ cells. We found that, indeed, a small subpopulation of myosin VI interacts with the AR (Fig. 4). These results suggest that myosin VI is an important factor modulating androgen-regulated gene expression through interaction with the AR.

\section{Discussion}

Based on the results published by Dunn and co-workers (6), we further analyzed the expression of myosin VI in prostate tissue using immunohistochemistry. Our results presented here are supportive to those reported earlier (6). Immunohistochemical staining confirmed the cytoplasmic/membranotic location of myosin VI protein expression. The staining pattern, however, showed no obvious differences between samples of benign and malignant prostate, indicating no practical appliance in routine histopathological differential diagnosis.

In our previous publication (8), we detected downregulation of several known androgen-regulated genes in the transformed LNCaP cell line variant. These included PSA and TMPRSS2. Further, the expression of AR was low in transformed LNCaP cells (8). Dunn and colleagues (6) observed that myosin VI protein expression in different cell lines positively correlates with the presence of AR. These results are supportive of our array results in LNCaP cell line variants, as both AR and myosin VI expression were downregulated in the transformed cell line variant (8). We then noted that myosin VI knock-down results in a decrease in AR expression. We selected proteins previously linked to myosin VI expression for this analysis. AR was selected based on its gene expression differences in LNCaP cell line variants (8). E-cadherin was selected because myosin VI depletion in Drosophila reduces the protein level of E-cadherin (11). Myosin VI downregulation did not affect to the expression of E-cadherin protein. Myosin VI has previously been linked to endocytosis (12) and endocytosis has been shown to play a role in the cellular uptake of sex steroids (13). Furthermore, AR is linked to the actin cytoskeleton via filamin, but little is known about the mechanism of cytoplasmic translocation or associated molecules that coordinate movement of the activated AR to the nucleus (14). In respect of its movement direction, myosin VI is an ideal candidate protein for participating in the AR translocation to the nucleus and we suppose it also participates in the androgen-induced transcription complex. These results and the potential impact of AR autoregulation suggested myosin VI is a regulator of androgen availability in the nucleus. Unfortunately, we were not able to detect a statistically significant decrease in testosterone uptake of LNCaP cells after myosin VI knock-down.

Myosin VI downregulation did not significantly decrease the availability of testosterone within the cell via testosterone uptake. Therefore, the autoregulation of AR was not suggested as an explanation for the decreased AR expression in myosin VI knocked-down cells. In addition, there is no evidence for the androgen regulated expression of myosin VI $(15,16$; our experiments, data not shown). Thus it seems logical that myosin VI plays a role in the regulation of ARmediated gene expression but is not androgen regulated itself.

Myosin VI has been shown to be present in the nucleus and has been detected in the RNA polymerase II-complex (5). AR and RNA polymerase II were also shown to be present in the same transcription complex $(17,18)$. Based on this indirect evidence of myosin VI and AR being present in the same transcription complex, we examined the interaction between myosin VI and AR. We were able to show the interaction between the AR and myosin VI proteins. Although our results undoubtedly indicate the interaction of only a small subpopulation of these proteins, it does not mean that the functional significance is likely to be modest. Immunoprecipitation is a challenging method and weak interactions are easily lost with unfavorable sample handling. 
Over time, a vast majority of prostate cancers treated primarily with hormonal therapies emerge in a hormone refractory disease state. This is an unsolved dilemma in the treatment of prostate cancer outside of curative treatments. Hormone-refractory prostate cancer is hypothesized to be a consequence of the overexpression of genes through AR mediated gene expression, expression of survival genes without AR-mediated gene expression, or hormone-refractory cells that arise from primarily androgen-independent cell clones (19). It is undoubtedly true that AR has a central role in prostate carcinogenesis and thus myosin VI is a potential therapeutic target for prostate cancer as it could be used as a modulator of AR-dependent gene expression.

We noted that androgen-dependent gene expression was affected by myosin VI knock-down. Further, we were able to show the interaction between the AR and myosin VI proteins. We propose that myosin VI is a coactivator of the AR. Thus, myosin VI is a potential therapeutic target for prostate cancer as it could be used as a modulator of AR-dependent gene expression.

\section{Acknowledgements}

We thank Sarah Vreugde and Helmut Pospiech for their valuable advice concerning the immunoprecipitation experiments as well as Erja Tomperi, Mirja Vahera, Malla Tolppanen, Marjaliisa Martti and Marjaana Vuoristo for their technical assistance. This study was supported by a grant from the Päivikki and Sakari Sohlberg Foundation and a state subsidy for the Oulu University Hospital.

\section{References}

1. Wells AL, Lin AW, Chen LQ, Safer D, Cain SM, Hasson T, Carragher BO, Milligan RA and Sweeney HL: Myosin VI is an actin-based motor that moves backwards. Nature 401: 505-508, 1999.

2. Aschenbrenner L, Naccache $\mathrm{SN}$ and Hasson T: Uncoated endocytic vesicles require the unconventional myosin, Myo6, for rapid transport through actin barriers. Mol Biol Cell 15: 2253-2263, 2004.

3. Yoshida H, Cheng W, Hung J, Montell D, Geisbrecht E, Rosen D, Liu J and Naora H: Lessons from border cell migration in the drosophila ovary: a role for myosin VI in dissemination of human ovarian cancer. Proc Natl Acad Sci USA 101: 81448149, 2004.

4. Millo H, Leaper K, Lazou V and Bownes M: Myosin VI plays a role in cell-cell adhesion during epithelial morphogenesis. Mech Dev 121: 1335-1351, 2004
5. Vreugde S, Ferrai C, Miluzio A, Hauben E, Marchisio PC, Crippa MP, Bussi M and Biffo S: Nuclear myosin VI enhances RNA polymerase II-dependent transcription. Mol Cell 23: 749-755, 2006.

6. Dunn TA, Chen S, Faith DA, Hicks JL, Platz EA, Chen Y, Ewing CM, Sauvageot J, Isaacs WB, De Marzo AM and Luo J: A novel role of myosin VI in human prostate cancer. Am J Pathol 169: 1843-1854, 2006.

7. Demichelis F, Setlur SR, Beroukhim R, Perner S, Korbel JO, Lafargue CJ, Pflueger D, Pina C, Hofer MD, Sboner A, Svensson MA, Rickman DS, Urban A, Snyder M, Meyerson M, Lee C, Gerstein MB, Kuefer R and Rubin MA: Distinct genomic aberrations associated with ERG rearranged prostate cancer. Genes Chromosomes Cancer 48: 366-380, 2009.

8. Vaarala MH, Porvari K, Kyllonen A and Vihko P: Differentially expressed genes in two LNCaP prostate cancer cell lines reflecting changes during prostate cancer progression. Lab Invest 80: 1259-1268, 2000 .

9. Takeda H, Nakamoto T, Kokontis J, Chodak GW and Chang C: Autoregulation of androgen receptor expression in rodent prostate: Immunohistochemical and in situ hybridization analysis. Biochem Biophys Res Commun 177: 488-496, 1991.

10. Wolf DA, Herzinger T, Hermeking H, Blaschke D and Horz W: Transcriptional and posttranscriptional regulation of human androgen receptor expression by androgen. Mol Endocrinol 7: 924-936, 1993.

11. Geisbrecht ER and Montell DJ: Myosin VI is required for Ecadherin-mediated border cell migration. Nat Cell Biol 4: 616-620, 2002.

12. Buss F, Arden SD, Lindsay M, Luzio JP and Kendrick-Jones J: Myosin VI isoform localized to clathrin-coated vesicles with a role in clathrin-mediated endocytosis. EMBO J 20: 3676-3684, 2001.

13. Hammes A, Andreassen TK, Spoelgen R, Raila J, Hubner N, Schulz H, Metzger J, Schweigert FJ, Luppa PB, Nykjaer A and Willnow TE: Role of endocytosis in cellular uptake of sex steroids. Cell 122: 751-762, 2005

14. Ozanne DM, Brady ME, Cook S, Gaughan L, Neal DE and Robson CN: Androgen receptor nuclear translocation is facilitated by the f-actin cross-linking protein filamin. Mol Endocrinol 14: $1618-1626,2000$.

15. Velasco AM, Gillis KA, Li Y, Brown EL, Sadler TM, Achilleos M, Greenberger LM, Frost P, Bai W and Zhang Y: Identification and validation of novel androgen-regulated genes in prostate cancer. Endocrinology 145: 3913-3924, 2004.

16. Holzbeierlein J, Lal P, LaTulippe E, Smith A, Satagopan J, Zhang L, Ryan C, Smith S, Scher H, Scardino P, Reuter V and Gerald WL: Gene expression analysis of human prostate carcinoma during hormonal therapy identifies androgenresponsive genes and mechanisms of therapy resistance. Am J Pathol 164: 217-227, 2004.

17. Shang Y, Myers M and Brown M: Formation of the androgen receptor transcription complex. Mol Cell 9: 601-610, 2002.

18. Wang Q, Carroll JS and Brown M: Spatial and temporal recruitment of androgen receptor and its coactivators involves chromosomal looping and polymerase tracking. Mol Cell 19: 631-642, 2005.

19. Feldman BJ and Feldman D: The development of androgenindependent prostate cancer. Nat Rev Cancer 1: 34-45, 2001. 